\title{
COMPARISON OF TUBERCULIN TEST POSITIVITY IN PULMONARY TUBERCULOSIS WITH HIV SEROPOSITIVE AND SERONEGATIVE PATIENTS
}

B.V. Shamsundar, Venkatesha. D, Anuradha. K.

1. Assistant Professor. Department of Microbiology, Mysore medical college. Mysore.

2. Professor. Department of Microbiology, Mysore Medical College. Mysore.

3. Associate Professor. Department of Microbiology, Mysore Medical College. Mysore.

\section{CORRESPONDING AUTHOR:}

Dr. Shamsundar,

M-16 -2stage,

Kuvempunagar, Mysore.

E-mail: shamsundarmysore@gmail.com

ABSTRACT:- BACKGROUND: HIV \& Tuberculosis is a common co- infection that we come across in developing countries. Diagnosis is done by demonstration of acid fast bacilli (AFB) \&Tuberculin skin test (TST). Skin test depends on cell mediated immune response which is generally compromised in HIV infected. OBJECTIVE: To compare the demonstration of AFB \&TST reactivity in tuberculosis patients who are HIV seropositive \& seronegative MATERIALS \& METHODS: The study was conducted in the tuberculosis hospital which is attached to the Mysore medical college, Mysore. All patients clinically suspected or diagnostically confirmed as pulmonary tuberculosis were subjected for HIV screening test as per NACO guidelines.Total of 200 patients included for the study out of which 100 each were HIV seropositive \& seronegative. They were subjected for microscopic examination of sputum\& TST. Sputum microscopy was performed as per RNTCP guidelines. PPD antigen was injected intra- dermally on the left forearm \& read after 48 hours \& results were noted down. RESULTS: Study group divided into two categories. Category A: Pulmonary tuberculosis patients with HIV seropositivity Category B: Pulmonary tuberculosis patients with HIV seronegativity. Male preponderance was observed in both $79 \%$ \& $70 \%$ with the mean age of $32.7 \pm 7.3$ years, in females seronegativity was more i.e. $30 \%$ compared to $21 \%$ in seropositive with mean age of $29.3 \pm$ 5.6 years. AFB demonstrated by Sputum microscopy in 99\% HIV seronegatives \& 54\% of HIV seropositives. TST results classified into groups with No response, induration of $1-5 \mathrm{~mm}, 6-9 \mathrm{~mm} \&$ $>10 \mathrm{~mm}$. Among category A 9 of them exhibited No response,32 of them 1-5mm,27 of them 6-9mm \& 32 of them $>10 \mathrm{~mm}$. All category B has responded to TST with only one patient with $1-5 \mathrm{~mm}, 25$ with $6-9 \mathrm{~mm}, 74$ with $>10 \mathrm{~mm}$. DISCUSSION: There is statistically significant difference $(\mathrm{p}>0.05)$ in TST \&AFB demonstration in pulmonary tuberculosis patients with HIV seropositive \& seronegative. Sensitivity of TST is reduced as TST is indicator of cell mediated immune response which is generally compromised in HIV seropositive. Demonstration of AFB is also reduced in HIV seropositive cases. CONCLUSION: TST \& demonstration of AFB are common tests done to screen for HIV-TB co infection in HIV seropositive. As the sensitivity of these tests are reduced in HIV seropositive it needs to be interpreted with care.

KEY WORDS: tuberculin skin test, pulmonary tuberculosis, HIV seropositive, HIV seronegative 


\section{ORIGINAL ARTICLE}

INTRODUCTION: Tuberculosis is the commonest opportunistic infection occurring among HIV positive persons in India and it is estimated that $60-70 \%$ of HIV positive persons will develop tuberculosis in life time. ${ }^{1}$

Reactivated tuberculosis is more among HIV infected than non-HIV infected. ${ }^{2}$ HIV infection increases replication of mycobacterium tuberculosis in the human host and M. tuberculosis infection enhances HIV replication. As HIV disease progress, the number of T4 cells declines, correlating with a reduction in macrophage activity against mycobacterial antigens, the loss of Langerhans giant cells, epitheloid macrophages, granuloma formation and a shift from pauci-bacillary to a multibacillary state. $^{3}$

Several studies from different parts of the country have also documented high HIV sero prevalence rates among tuberculosis patients. Late occurrence of HIV associated tuberculosis with greater impairment of cell mediated immunity presents with the typical features like negative tuberculin reaction, mediastinal or hilar lymph nodes enlargement and lower zone infiltration or diffuse infiltration or cavitation. ${ }^{3}$

Due to qualitative and quantitative defects of $\mathrm{CD}_{4}$ cells in the course of HIV infection, tuberculin responsiveness even in the presence of tuberculosis is bound to be diminished. Due to this fact CDC in 1993 recommended that an induration of $5 \mathrm{~mm}$ or more in tuberculin test should be considered positive. ${ }^{4}$

The present study was undertaken to compare the demonstration of Acid fast bacilli \& tubercular skin test in pulmonary tuberculosis patients who are HIV seropositive \& seronegative.

MATERIALS \& METHODS: Patients admitted to the hospital between the age group of 18-55years with diagnostically confirmed cases or clinical features suggestive of pulmonary tuberculosis are included as study group. Patients who are on antituberculosis treatment, steroid or other immunosuppressive agents, pregnancy with tuberculosis \& extrapulmonary tuberculosis are excluded from the study.

After obtaining institutional ethical clearance \& taking informed consent from the study group detailed history regarding their age, occupation, presenting symptoms, annual income etc were entered in the proforma. Radiological findings were noted down.

All the patients with pulmonary tuberculosis were subjected for HIV serotesting as per NACO guidelines after taking the consent.

200 pulmonary tuberculosis patients were included as study group, out of which 100 were HIV seropositive \& 100 HIV seronegative status. Each patient was subjected to sputum microscopic examination \& TST.

Sputum microscopic examination was done as per RNTCP guidelines after collecting three samples to demonstrate acid fast bacilli \& positive were graded.

Tuberculin skin test was performed by Mantoux technique. Volar surface of the patients left forearm was selected \& under aseptic conditions with disposable needle $0.1 \mathrm{ml}$ of PPD antigen was injected with needle bevel upwards intradermally, and examined after 48 hours for the delayed hypersensitivity reaction.

Readings were taken in good light with the forearm of the patient slightly flexed at the elbow. The basis of the reading was the presence or absence of induration which is determined by pen method.5,6 


\section{ORIGINAL ARTICLE}

RESULTS: The study group of 200 patients were divided into two category as category A pulmonary tuberculosis with HIV seropositive \& category B pulmonary tuberculosis with HIV seronegative

Pulmonary tuberculosis was seen with male preponderance in both HIV seropositive \& seronegative group with $79 \% \& 70 \%$ respectively, in females seronegative is higher $30 \%$ than seropositives $21 \%$.( Table 1 )

The mean age among males suffering from pulmonary tuberculosis and HIV seropositivity was $32.7 \pm 7.3$ years, while among females it was $29.3 \pm 5.6$ years. The difference in the mean age was statistically significant $(\mathrm{p}<0.05)$. (Table 2 )

Seropositive cases with tuberculosis are found more between age group of 21-30years with $44 \%$. Among males $41.77 \%$ was seen in $31-40 y r s, 66.66 \%$ of females in $21-30 y r s$ age group. (Table 3)

In our study sputum positivity was observed in 54\% of category A and, $99 \%$ category B. (table-4)

Among category A patients $9 \%$ showed no tuberculin reaction (anergy), 32\% showed induration size between $1-5 \mathrm{~mm}, 27 \%$ showed induration size between $6-9 \mathrm{~mm}, 32 \%$ showed induration size of 10 or more than $10 \mathrm{~mm}$. (Table -5)

Category B patients, anergy was not noticed,1 case showed induration of 1-5mm , 25\% showed induration size between $6-9 \mathrm{~mm}, 74 \%$ showed induration size of 10 or more than $10 \mathrm{~mm}$ ( table 6).

Comparison of sputum microscopy and tuberculin test done sputum and tuberculin positivity was observed $44 \%$ in category A whereas category B showed $74 \%$. (Table 7 )

DISCUSSION: Mycobacterial infections are common AIDS defining events. Latent tuberculosis in HIV infected patients is generally detected by TST and those who are positive have chance of going into active tuberculosis. The present study is conducted to compare the tuberculin skin test with that of demonstration of acid fast bacilli in pulmonary tuberculosis patients who are HIV seropositive \& seronegative. Study group comprised of 200 patients in which 100 each of HIV seropositive and seronegative with pulmonary tuberculosis. $44 \%$ of the patients were in the age group of 21-30 years followed by 38\% 31-40 years indicating that sexually active age group are commonly affected. ${ }^{7}$ which correlates with study of Purohit S Det al ${ }^{8}$

Sputum positivity is generally less common in HIV positive patients when compared to seronegative pulmonary tuberculosis patients. Cavitatory lesion is less common in HIV/AIDS patients with pulmonary tuberculosis, instead there will be infiltrative type of lesion. ${ }^{9}$

HIV positive patients have been reported to have a lower yield of AFB smears, because they excreted slightly fewer organisms per milliliter of sputum than did HIV-negative patients. As the bacillary count decreases due to the above condition, sputum will be negative for AFB. ${ }^{10,11}$

Various studies compared Smear positivity in seropositive and seronegative patients. Robert L. Colebunders et al 12 , showed $42 \%$ positive in seropositives whereas $60 \%$ in seronegatives. K.C.mohanty et al $47.80 \%$ and $70.12 \%$ positivity in seropositives and seronegatives respectively ${ }^{13}$. Francoise Kramer et al, Praveen Kumar et al, R. Prasad et al studied only in HIV seropositives with $61 \%, 21.4 \%, 62.5 \%$ respectively 14,15,16.In our study 54\% with HIV seropositivity 99\% with HIV seronegative status had shown sputum positivity for acid fast bacilli. This study correlates with other studies . 


\section{ORIGINAL ARTICLE}

HIV seropositive pulmonary tuberculosis patients shows decreased tuberculin response due to specific depletion of $\mathrm{CD}_{4}$ cells as a result of $\mathrm{HIV}$ infection. $\mathrm{CD}_{4}$ cells that produce interleukin- 2 and IFN- $\gamma$ are thought to be essential for the development of positive tuberculin skin test. ${ }^{17}$ So Tuberculin positivity is consistently lower in HIV seropositive patients when compared to HIV seronegative patients. This has been demonstrated by the various studies conducted.

The percentage of anergy as noticed by various workers ranged from $26.54 \%$ to $53.5 \%$. Robert L. Colebunders et al. 33\% ${ }^{12}$ Neil M.H. Graham et al $48.52 \%{ }^{18}$ Yadinl Mukadi et al. 26.54\% ${ }^{19}$ K.C. Mohanty et al. 36.84\% ${ }^{20}$ J.E. Malkin53.5\%21.In the present study $9 \%$ of category A showed nil reaction (anergy), and no anergy was noticed in category B patients. The decreased percentage of anergy in the present study could be that probably the CMI of HIV seropositive patients are still not that compromised. ${ }^{17}$

Decreased CD4 cell count $\left(<100 \mathrm{CD}_{4}\right.$ cell $\left./ \mathrm{mL}\right)$ cause diminished cytotoxic cell activity, decreased production of interleukin-2, reduced expression of interleukin-2 receptors and diminished monocyte macrophage function. Altered lipid environment and lipid content of cell membrane interfere with mechanism of activation of signal transfer from helper to cytotoxic cell All this mechanism could contribute to the cutaneous anergy in HIV sero positive pulmonary tuberculosis patients. ${ }^{4,17}$

According to the CDC Criteria, induration of more than or equal to $5 \mathrm{~mm}$ to tuberculin injection is taken as positive reaction in case of HIV seropositive patients and induration of more than $10 \mathrm{~mm}$ is taken as positive in pulmonary tuberculosis patients without HIV infection. ${ }^{18}$

In the early stage of HIV infection, $\mathrm{CD}_{4}$ cell count will still be high and hence tuberculin reactivity is still positive ( $\geq 5 \mathrm{~mm}$ ). This could be the reason for tuberculin positivity in the sero positive pulmonary tuberculosis patients. Various immunosuppressive mechanisms are implicated in the depression of delayed hypersensitivity reaction during active tuberculosis infection. Nonspecific suppression mediated by circulating immunocomplex containing mycobacterial polysaccharide. There is compartmentalization of antigen specific lymphocytes in the lymph nodes of tuberculin anergic patients. Production of immunosuppressive prostaglandin $\mathrm{E}_{2}$ by activated monocytes. Increased production of IL-I by activated monocytes thus leading to immunosuppression. There is PPD specific suppression by Fc receptor bearing lymphocytes. All this immunosuppressive mechanism may result in depression of tuberculin induced blastogenesis, and decreased production of IL-2, generation of IL-2 receptor, and hence a negative tuberculin test in some patients with active tuberculosis with HIV negative sero status.Sometimes false negative tuberculin reaction can occur in both pulmonary tuberculosis patients with HIV seropositivity and HIV seronegativity. ${ }^{22}$

Category A 32\% had induration of $1-5 \mathrm{~mm}, 27 \%$ 6-9mm and $32 \%$ had $>10 \mathrm{~mm}$ if we consider the CDC guidelines to take $>5 \mathrm{~mm}$ as positive in HIV seropositive then $59 \%$ will be considered as positive. Category B 74\% showed induration of $>10 \mathrm{~mm}, 24 \% 6-9 \mathrm{~mm}, 1$ showed between 1$5 \mathrm{~mm}$.These results are statistically significant with $\mathrm{p}$ value $<0.005$.

Tuberculin positivity in HIV seropositive patients ranged from $12 \%$ to $52.30 \%$.In the present study, 59\% HIV positive serostatus showed positive tuberculin reaction .This correlates with the study done by K.C. Mohanty et al who reported $52.30 \%{ }^{20}$ 


\section{ORIGINAL ARTICLE}

In the HIV seronegative patients, the tuberculin positivity ranged from $25 \%$ to $93 \%$.In the present study $74 \%$ pulmonary tuberculosis patients with HIV seronegativity showed positive tuberculin reaction. This correlates well with the study done by J.K. Malkin et al they reported $74.5 \%$ positivity .21

According to the study conducted by J.E. Malkin et al $25.5 \%$ of pulmonary tuberculosis patients with HIV seronegative status showed a negative tuberculin response $(<10 \mathrm{~mm})$ instead of showing positive tuberculin response. ${ }^{21}$ In the present study, also we observed similar results $26 \%$ pulmonary tuberculosis patients with HIV seronegative status showed a negative tuberculin response $(<10 \mathrm{~mm})$.

The important tests done for routine diagnosis of pulmonary tuberculosis are tuberculin skin test and sputum AFB positivity. Category A patients showed both the tests positive in $44 \%$ and negative in $31 \%$.Whereas in category B $74 \%$ showed both the tests positive. This clearly shows impairment of immune response does interfere with the results.

CONCLUSION: Even today we consider demonstration of AFB in sputum specimen and tuberculin test as important diagnostic tests to diagnose pulmonary tuberculosis. In HIV seropositives these are not very useful as we may miss considerable number of cases as results of these tests depends on various host factors. As we have observed in the present study only in about $50 \%$ it will be useful. There is a need for further study correlating with CD4 count which will give information that at which stage of disease still we can rely on these tests.

Table - 1: Showing sex wise distribution in various categories

\begin{tabular}{|l|l|l|l|l|l|}
\hline \multirow{2}{*}{ Category wise } & \multicolumn{3}{|l|}{ Sex } & \multirow{2}{*}{ Total number of cases } \\
\cline { 2 - 6 } & Male & $\%$ & Female & $\%$ & \\
\hline Category A & 79 & 79 & 21 & 21 & 100 \\
\hline Category B & 70 & 70 & 30 & 30 & 100 \\
\hline
\end{tabular}

(Category A: Pulmonary tuberculosis patients with HIV seropositivity)

(Category B: Pulmonary tuberculosis patients with HIV seronegativity)

Table - 2: Showing the mean age and standard deviation of males and females

\begin{tabular}{|l|l|l|}
\hline Sex & Mean (years) & Standard Deviation (years) \\
\hline Male & 32.7 & 7.3 \\
\hline Female & 29.3 & 5.6 \\
\hline
\end{tabular}

$(\mathrm{t}=2.31 \mathrm{~d} . \mathrm{f} .=98)$

$\mathrm{p}<0.05$ (Significant) 


\section{ORIGINAL ARTICLE}

Table-3 Showing age and sex wise distribution of category $A$

\begin{tabular}{|l|l|l|l|l|l|l|}
\hline \multirow{2}{*}{ Age (years) } & \multicolumn{2}{|l|}{ Male (N=79) } & \multicolumn{2}{|l|}{ Female (N=21) } & \multirow{2}{*}{ Total } & \multirow{2}{*}{ Percentage (\%) } \\
\cline { 2 - 6 } & Number & $\%$ & Number & $\%$ & & \\
\hline$<20$ & 02 & 2.53 & 00 & 0 & 02 & 02 \\
\hline $21-30$ & 30 & 37.97 & 14 & 66.66 & 44 & 44 \\
\hline $31-40$ & 33 & 41.77 & 05 & 23.80 & 38 & 38 \\
\hline $41-50$ & 11 & 14.00 & 02 & 9.52 & 13 & 13 \\
\hline$>50$ & 03 & 3.79 & 00 & 00 & 03 & 03 \\
\hline Total & 79 & 100 & 21 & 100 & 100 & 100 \\
\hline
\end{tabular}

Table - 4: Showing sputum for AFB positivity among various categories

\begin{tabular}{|l|l|l|l|l|l|l|l|}
\hline \multirow{2}{*}{ Category } & \multicolumn{5}{|l|}{ Sputum positive cases } & \multicolumn{4}{|l|}{ Sex wise distribution } & \multirow{2}{*}{ Total cases studied } \\
\cline { 2 - 8 } & Total & $\%$ & Male & $\%$ & Female & $\%$ & \\
\hline Category A & 54 & 54 & 44 & 81.48 & 10 & 18.52 & 100 \\
\hline Category B & 99 & 99 & 70 & 70.71 & 29 & 29.29 & 100 \\
\hline
\end{tabular}

$\mathrm{p}<0.05$ (Significant)

Table - 5: Showing tuberculin reactivity among various categories

$\mathrm{p}<0.05$ (significant)

\begin{tabular}{|l|l|l|l|l|}
\hline Category & Nil reaction & $1-5 \mathrm{~mm}$ & $6-9 \mathrm{~mm}$ & $>10 \mathrm{~mm}$ \\
\cline { 2 - 5 } & No(\%) & No(\%) & No(\%) & No(\%) \\
\hline Category A & $9(9)$ & $32(32)$ & $27(27)$ & $32(32)$ \\
\hline Category B & & $01(1)$ & $25(25)$ & $74(74)$ \\
\hline
\end{tabular}

Table - 6: Showing sputum for AFB positivity and tuberculin reactivity in various categories

\begin{tabular}{|l|l|l|l|l|l|}
\hline \multirow{2}{*}{ Category } & \multirow{2}{*}{ Sex } & \multirow{2}{*}{ Sputum for AFB } & \multicolumn{2}{l|}{ Induration size $(\mathrm{mm})$} & \multicolumn{2}{l|}{} \\
\cline { 4 - 6 } & & & $\leq \mathrm{mm}$ & $6-9 \mathrm{~mm}$ & $\geq 10 \mathrm{~mm}$ \\
\hline \multirow{4}{*}{ Category A (Case studied 100) } & Male & $44(81.48 \%)$ & $33(80.5 \%)$ & $18(66.7 \%)$ & $28(87.5 \%)$ \\
\cline { 2 - 6 } & Female & $10(18.52 \%)$ & $08(19.5 \%)$ & $09(33.3 \%)$ & $04(12.5 \%)$ \\
\cline { 2 - 6 } & Total & $54(54 \%)$ & $41(41 \%)$ & $27(27 \%)$ & $32(32 \%)$ \\
\hline \multirow{3}{*}{$\begin{array}{l}\text { Category B } \\
\text { (Case studied 100) }\end{array}$} & Male & $70(70.71 \%)$ & $01(100 \%)$ & $21(84 \%)$ & $48(64.9 \%)$ \\
\cline { 2 - 6 } & Female & $29(29.29 \%)$ & Nil & $04(16 \%)$ & $26(35.1 \%)$ \\
\cline { 2 - 6 } & Total & $99(99 \%)$ & $01(1 \%)$ & $25(25 \%)$ & $74(74 \%)$ \\
\hline
\end{tabular}

\section{BIBLIOGRAPHY:}




\section{ORIGINAL ARTICLE}

1. Sowmya Swaminathan, Sangeetha M et al. Pulmonary tuberculosis in HIV positive individuals: Preliminary report on clinical features and response to treatment. Ind J of Tub 2002; 49: 189193.

2. Menon MPS. A new look at the immunology of tuberculosis. Ind J of Tub 1997; 44: 3-8.

3. Drobniewsk A, Pozniak AL, Uttley AHC. Tuberculosis and AIDS. J Med Microbiology 1995; 43: 85-91.

4. Hardally R Hegde. Anergy and Tuberculosis: Introspection of a theory. Ind J of Paediatrics 1989; 122: 123-129.

5. Theresa J Jordan, Gnana Sunderam, Lannie Thomas, Lee B Reichman. Tuberculin reaction size measurement by the pen method compared to traditional palpation. Chest 1987; 92: 234-235.

6. Joseph E Sokal. Measurement of delayed skin test responses. The New England Journal of Medicine. 1975; 293(10): 501-502.

7. Joshi PL. HIV Epidemiology. HIV testing manual NACO, Govt. of India, New Delhi 1999: 8.

8. Purohit SD, Gupta RC, Bhatara VK. Pulmonary tuberculosis and human immunodeficiency virus infection in Ajmer. Lung India 1996; XIV, No. 3: 113-120.

9. Mario C Raviglione, Richard J O' Breinin Harrison's Principal of internal medicine Vol. 1, 16 ${ }^{\text {th }}$ ed. (McGraw-Hill Companies, Inc, USA) 2005: 959.

10. William N Rom, Stuart M Garry. Tuberculosis, First edition [Little, Brown and Company (inc) USA] 1996: 451.

11. Ananthnarayan R, Paniker CKJ. Text book of Microbiology. $7^{\text {th }}$ ed. Orient Longman, Hyderabad, 2005: 329-330.

12. Robert L Colebunders, Robert W Ryder, Nzilanzilambi, et al. HIV infection in patients with tuberculosis in Kinshasa. Zaire. Am Rev Respir Dis 1989; 139: 1082-1085.

13. Mohanthy KC, Sudhir Nair, Tushar Sahara Budhe. Changing trend of HIV infection in patients with respiratory disease in Bombay since 1988. Ind J Tub 1994; 41: 147-150.

14. Francoise Kramer, Tamara Modileusky, Abdul R Waliany, John M Leedom, Peter F Barners. Delayed diagnosis of tuberculosis in patients with human immunodeficiency virus infection. The American Journal of Medicine 1990 Oct; 89: 451-456.

15. Praveen Kumar, Niraj Sharma, Sudhakar Patnaik. Clinical profile of tuberculosis in patients with HIV infection/ AIDS. Indian J Chest Dis and Allied Sci 2002; 44: 159-163.

16. Prasad R, Saini JK, Kannavjia RK, Sarin S, Suryakant, Kulshreshth R et al. Trend of HIV infection in patients with pulmonary tuberculosis in Lucknow Area. Ind J Tub 2003; 50: 3941.

17. Brenda E Jones, Summer MM Young, Diana-antoniskis, Paul T Davidson, Francoise Kramer, Peter F Barnes. Relationship of the manifestation of tuberculosis to $\mathrm{CD}_{4}$ cell counts in patients with Human immunodeficiency virus infection. Am Rev Respir Dis 1993; 148: 1292-1297.

18. Neil H Graham, Kenard E Nelsen, Lizasoloman, Margaret Bonds, Rosetta RN, Joseph Scavotto et al. Prevalence of tuberculin positivity and skin anergy in HIV-I seropositive and seronegative intravenous drug users. JAMA 1992; 267(3): 369-373.

19. Yadiul $\mathrm{Mu}$ Kadi, Joseph $\mathrm{H}$ perriens, Michael Estlouis, Christopher Brown, Jacques Prignot, Jean-Claude Willame et al. Spectrum of immunodeficiency in HIV-infected patients with pulmonary tuberculosis in Zaire. The Lancet 1993; 342: 143-146. 


\section{ORIGINAL ARTICLE}

20. Mohanty KC, Sundrani RM, Sudhir Nair. HIV infection in patients with respiratory disease. Ind J Tub 1993; 40: 5-11.

21. Malkin JE, Prazuck T, Simonnet F, Yameogo M, Rocherear A, Ayeroue J et al. Tuberculosis and human immunodeficiency virus infection in West Burkina Faso : Clinical presentation and Clinical evolution. Int J Tuberc Lung dis 1997; 1(1): 68-74.

22. Sharma SK. Tuberculosis, $1^{\text {st }}$ edition [Jaypee brother's Ltd- New Delhi] 2001; 120-126. 